\title{
Chomsky with Lewis: Human Nature, Science and Language Origin
}

\author{
MARCIANO ESCUTIA \\ Universidad Complutense de Madrid \\ mescutia@ucm.es \\ ORCID: 0000-0002-2725-0726
}

\begin{abstract}
This article, in its first part, summarizes Noam Chomsky's ideas about human nature and their ethico-political consequences, language and its origin and the scope and limitations of science. Then, in the second part, and based on the author C. S. Lewis, a proposal will be made about the possible existence of an infused spiritual soul in humans and how it could connect with the linguist's ideas with respect to the origin of language. It will also serve to supply with some realism Chomsky's overly optimistic view about human nature.
\end{abstract}

Key words: Humanity; language origin; first hominids; original sin.

Resumen: Este artículo, en su parte primera, resume las ideas de Noam Chomsky sobre la naturaleza humana y sus implicaciones ético-políticas, el lenguaje y su origen, y el alcance y limitaciones de la ciencia. En la segunda parte, y en base al autor C. S. Lewis, se examina una propuesta sobre la posible existencia de un alma espiritual infusa y su posible conexión con las ideas del lingüista respecto al origen del lenguaje. Asimismo, se intenta compensar con algo más de realismo la visión demasiado optimista de Chomsky sobre la naturaleza humana.

Palabras clave: naturaleza humana; origen del lenguaje; primeros homínidos; pecado original. 
In the first part of this article, we will summarize the main ideas of Noam Chomsky, the famous linguist and political philosopher, concerning human nature, language and the limits of scientific inquiry. ${ }^{1}$ They are necessary to provide a background upon which a complementary proposal inspired by the writer and professor Clive S. Lewis will be projected. The goal is to explain how Chomsky's ideas with respect to the origin of language in the mind -along with his underlying tenets about human nature- and Lewis's with respect to the origin and fall of mankind can complement each other.

\section{Chomsky, the linguistic scientist}

Chomsky, one of the leaders of the so-called "cognitive revolution" of the 1950s, is the pioneer of the distinction between, on the one hand, the subconscious mental grammar, developing in the brain similarly to a computational system as a result of being exposed to natural linguistic data, and, on the other, the descriptive formalization of that grammar made by linguists. An innate genetic endowment for language is required, he says, and he calls it Universal Grammar because it is the most likely way whereby a child can specifically identify, more or less consciously, linguistic stimuli in their habitat and "grow" the corresponding creative linguistic human capacity according to the linguistic input received. Other animals are not capable of recognizing the specificity of linguistic stimuli even if exposed to the same input. He thinks that this explains why children from any race who have been transplanted from their place of origin to another country acquire the new language effortlessly.

\footnotetext{
They are not taken from a ready-made compilation of them but are drawn from written, audio and video sources as referenced at the end. Because his well-known ideas are interspersed in such various sources, no specific reference to the latter will be made in the text in some cases. Although our main written source for the ideas about language, human nature and the limits of science have been Noam Chomsky (1975, 1992, 2005, 2012a, 2016a) and Neil Smith (2004), other related material has been drawn from the difficult-to-quote audiovisual ones, all included in the reference list. Still, some specific references to such sources will appear as footnotes. The rest of written sources will be specifically quoted.
} 
For Chomsky, the problem and program for linguistic research consists in formalizing the content of that innate genetic blueprint. In order to carry it out any language is useful because all of them are different externalized manifestations of the same capacity, independently of the concepts and cultural categories codified in them, which correspond to the specific physical and social environment where they have developed.

\section{Human nature}

Given his exclusively naturalistic outlook, Chomsky thinks that in order to examine human nature deeply one should subject humans to scientific experimentation, which is ethically non-viable. Still, he rejects comparing people and animals on equal terms since he recognizes a radical difference between the two. He gives the study of language a privileged place in this respect since it is an unparalleled, exclusively human property whose research does not pose any ethical problems.

Chomsky criticizes both Marxist thinkers like Gramsci and pragmatists such as Michel Foucault or Richard Rorty, who think there is no human nature but only ever-changing history. He particularly rejects this denial when it comes to the specifically high human mental functions. Though acknowledging human nature's varied realizations, he radically differs from those Marxists who reject a stable human nature as reactionary, warning that this position is the panacea of the ruling class. Certainly, if there is no human nature there is room for social engineering but not for freedom and creative capacity, both of which are inconceivable if such a nature cannot be objectively and rationally researched.

Chomsky points out that Marx firmly believed in human nature and from it he derives the need and right to exercise a personal and creative job for the good of the community, without having to be subject to state control. In this sense, his conception of human nature owes very much to Rousseau and his idea of the "noble savage". Social institutions, and particularly capitalistic ones, would stifle this natural tendency to create and to cooperate disinterestedly with others, thus causing alienation and 
hindering the establishment of communities living in harmony with one another. In a parallel fashion, his idea of language as an internal system to externalize thought making it explicit is a paradigm of creativity and productivity using finite means (sounds and words). Chomsky does not think of language primarily as an instrument designed for communication, as a species selective biological advantage, but rather as a manifestation of an innate creative urge.

Regarding creativity, Chomsky often cites the $16^{\text {th }}$ century Spanish doctor and philosopher Juan Huarte. The latter distinguishes the intelligence humans share with animals from a higher plane of intelligence possessed only by the former, as illustrated in the creative use of language, a creativity also instantiated in artistic and scientific activities. Chomsky wonders whether these are questions that fall within the scope of human understanding or are "nature's ultimate secrets" in Hume's expression, consigned to an obscurity in which they will ever remain. ${ }^{2}$

The reality of human nature is a non-negotiable starting point for him. Its exact properties may not be evident but it is impossible to prove that there is no intrinsic nature that constitutes the human essence. He acknowledges that a child in New York may be different from one in the Amazonia in how their mental categories are specified. Still, one has to wonder how both children can develop self-consciousness in any milieu they happen to grow up in and assimilate a specific, rich and complex culture through the limited and scattered stimuli they are exposed to. That is to say, prior to any type of culture there has to exist an organizational innate component in the mind.

In this outlook, not only does language appear as a brain specialization but, indeed, behind the great majority of human activities there is an innate rich structuring basis of the human mind organizing the perception of social reality, scientific reasoning, personality analysis, aesthetic and moral judgments. With respect to the latter, Chomsky underlines their generalizability, depth and subtlety as well as the great common denominator to all moral systems. All specialized complex systems, uniformly acquired through

2 Recently, he has called this kind of questions "Galileo's challenge” (see Chomsky 2016b, 10'56”). 
a limited action of the environment, lean on a strong and highly organized innate component. Therefore, there has to be a biological basis enabling the development of moral judgments and a theory of what is just. He adds that our moral schemas may be more or less complex and homogeneous but there are objective standards, as reflected in the lexicon, for instance, in the distinction between killing and murdering or rights and duties. The omnipresence of these terms in most languages clearly points to it.

In short, Chomsky advocates a fundamentally biological human nature which uniquely identifies us as human, shaping a series of universal mental capacities enabling us to acquire language, culture and ethics. Chomsky's clinging to human nature on the one hand, and his left-wing political views on the other, makes of him a controversial and troublesome figure because although the American academic world, especially that of the social sciences, leans toward the political left, it does not generally accept the existence of a stable human nature.

\section{The limits of science}

In the tradition of Newton, Locke, Hume or Bertrand Russell, Chomsky admits there are real "mysteries" or questions either intellectually insurmountable or even inconceivable because they are beyond cognitive reach. These are different from "problems", which remain within the limits of our understanding though many may not have been solved yet. From the former category he mentions free will, our esthetic and musical sense, and other aspects of human behavior opaque to rationalization. He thinks that we do not have a real understanding of the world because our scientific and intellectual capacities are probably genetically bounded.

Our very knowledge about the use of language to refer to the world is very limited as well. According to Chomsky, the study of intensionality, the reference of mental processes to the outside world, can be an intellectually insurmountable mystery. For example, the fact that a word like rat can refer to rats in the world, instead of, say, dogs or rivers, is due to an arbitrary link between a word form and actual instances of the animal. However, saying that 
rat selects rats does not clarify the nature of reference, which is dependent on our perception and ultimately our nature. That is, meaning as nature is something taken for granted in dictionaries and not derivable from the external physical world, which is greatly irrelevant to linguistic description. Children, as a result of innate cognitive powers, unlike animals, use words in a conceptually constrained way, in an Aristotelian kind of binomial way (matter and form), says Chomsky.

Likewise, the most interesting aspects of language do not escape mystery either, such as its free, creative use: how we are capable of freely producing and understanding new utterances appropriate to the concrete situation or formulating and comprehending as they arise ideas never expressed before. We can study the possible computational mechanisms involved in language and its interfaces with its analyzing and articulating systems but there is a plethora of linguistic and intellectual questions we are not even capable of posing to ourselves.

Thus, Chomsky maintains that the most important cognitive and interesting questions in life are taken for granted but are far from being accounted for and he even doubts they may be amenable to scientific explanation.

\section{Language Origin}

Chomsky's ideas on the origin of language lean on the homogeneity of the human genome, which would explain why all children develop language just by being exposed to linguistic input without being taught it. This homogeneity can be due, according to molecular paleontology and comparative genetics, to the recent hominization process, as genetic variation has been minimal in the last two hundred thousand years. There has occurred no significant evolutionary change since a small group of our ancestors (homo sapiens sapiens), probably related to the Khoisan peoples of southeastern Africa, separated from other humans and left Africa around sixty thousand years ago. In fact, those same migrations ended up as well in New Guinea and Australia, where the "primitive peoples" dwelling there are the same as us at all levels, with no cognitive difference whatsoever. Previous to that period 
there is no evidence about language. Thus, in such an extremely short time in evolutionary terms, there appears to have happened a sudden explosion of creative, symbolic and artistic activity, along with representations of meteorological and astronomical events and an accompanying complex social organization. These are all possible indicators of the emergence of language, as they are not likely to have arisen without it.

According to Chomsky, all this activity may be due to a "cognitive bigbang", the result of neural circuitry reorganization in our ancestors' brains whereby some non-specific natural principle of computational efficiency would have interacted with a genetic mutation, thus giving rise to Universal Grammar. His scientific program investigates whether language principles are really the outcome of applying some general computational principles, perhaps even shared by other species, to the result of that mutation. The upshot of such interaction would enable recursive enumeration, the transition from what is finite to what is infinite, by taking two mental objects and giving rise to a new one in an unlimited recursive process of merging (cf. Hauser, Chomsky \& Fitch 2002, 2005). He also believes that at the root of such big bang there might also be the emergence of arithmetic and musical capabilities, showing how both display, as language does, the same kind of underlying, hierarchically structured, combinatorial operations (Berwick \& Chomsky 2016). ${ }^{3}$ This transition cannot be achieved, according to Chomsky, by small and progressive adaptations guided by natural selection but it rather involves a brusque, sudden leap.

According to this "saltationist" hypothesis about the origin of language, that mutation happened in an individual with a series of mental categories already in place and capable of being exploited by language. While long term evolution leads to great complexity (for example, the development of locomotive members), a sudden leap of this type tends to give rise to a simple solution - because of the shortness of time involved - to the design

3 Ding et al. (2015) have recently found neurophysiological support for this language instinct theory showing that we make sense of strings of words because our brains combine words into constituents in a hierarchical manner-a process that reflects an 'internal grammar' mechanism such as that proposed by Chomsky. 
problems determined by the environment. In addition, the morpho-anatomical structures involved in the perception and production of language have not changed in hundreds of thousands of years (the phonation apparatus included, which he thinks has evolved independently of language). This little change in the circuitry of the brain allowed language to spring suddenly and, a short time after, humans must have left the African continent. This event would entail an evolutionary advantage not caused by environmental (external) pressures but rather internal ones involving brain growth (generally ascribed to a larger diet) and complexification.

This hypothesis entails a certain departure from mainstream Darwinism. As Chomsky and his co-authors state (Bohuil, Tatterstall, Chomsky \& Berwick 2014):

... the language faculty is an extremely recent acquisition in our lineage, and it was acquired not in the context of slow gradual modification of preexisting systems under natural selection but in a single, rapid, emergent event that built upon those prior systems but was not predicted by them...The relatively sudden origin of language poses difficulties that may be called 'Darwin's problem. ${ }^{4}$

Although language is one and the same - an extraterrestrial observer of humans in different parts of the world might conceivably think they all do the same thing when they speak, as Chomsky likes to observe - there exists for Chomsky an unexpected diversification among languages in the specification of this underlying mental capacity. Each has its own system of computational rules to externalize them, resulting in the variety of the different world tongues. His research program in the last sixty years, which has resulted in evolving different linguistic models, has tried to make this variety in the externalization of languages compatible and coherent with their underlying cognitive unity within the innate computational system framework of Generative Grammar. This externalization of language involves

4 This thesis finds support in studies about the sudden externalization of the symbolic mode of thinking found in prehistorical cave and rock art going hand in hand with the appearance of language (see Miyagawa et al 2018). 
imposing certain restrictions on the form of (external) language (see Berwick \& Chomsky 2016 for details).

Finally, another chomskyan idea about language -quite contrary to the prevalent social sciences paradigm - is that it is not the product of certain changing cultural or sociopolitical circumstances at all, thus predicting an unlimited and arbitrary variability within the languages of the world, which is not the case. In this sense, one should not confuse the evolution of language with that of human communication, as often tends to occur.

Therefore, Chomsky supports a theory of the evolving discontinuity of language, not as something progressively originating as an evolutionary advantage in communication and social cooperation but rather as a capacity emerging suddenly and facilitating the former. As such, it is something qualitatively different from other animal communication forms and encompasses such uniquely human features as self-conscience and a complex theory of mind, free will, social complexity and the striving after the question of meaning and its source in the universe. His thesis runs counter to those Darwinist biologists who think that all aspects of evolution always entail gradual changes. For them, language would evolve gradually after our split from other primates and all those expected - in the continuistic perspective - intermediate species with linguistic capacities would have become extinct, leaving no trace. It also differs from the standard model of the social sciences, which ascribes the origin of language primarily to the need for communication, as for Chomsky the essence and main use of language is internal, that of thinking in language, which can be externalized - at least - in speech, sign or whistled language. Both language production and perception access the internal language but cannot be identified with it as it involves other factors as well, including short-term memory.

\section{******}

In the second part of this article and having recourse to a text by C. S. Lewis, the famous writer and professor of comparative literature at Oxford in the first half of the twentieth century, a proposal will be presented both compatible and complementary with Chomsky's humanistic theses described above. 
Lewis also firmly supported the idea of a rational human nature subject to the Tao, in Confucian terms, or Natural Law, or the demands of the Practical Reason (Lewis 2014a). “This Tao”, writes Lewis, "which we must treat as an absolute, is simply a phenomenon like any other-the reflection upon the minds of our ancestors of the agricultural rhythm in which they lived or even of their physiology" (p. 24), that is, as a given from the development of humanity in history, much like Chomsky's conception of human nature. However, before trying to establish the connection and the contrast between these two authors, it will be necessary to present Chomsky's ideas about God and the supernatural.

\section{An honest and respectful agnostic}

Although Chomsky is an agnostic and does not believe in man's spiritual soul, he is not a militant and anti-religious zealot, such as are the representatives of modern scientific fundamentalism. Despite maintaining that what he understands as religious beliefs are irrational and consciously avoiding them, he acknowledges that many agents of good in the world are moved by religion, in spite of exceptions. He sympathizes with the fact that religion is something very important in a lot of peoples' lives because, besides its self-helping qualities, it responds to the need for the expression of many valuable elements of one's own personality. Furthermore, he points out, religion has often played a very positive part in the history of the world, mentioning, for example, how the Catholic Church has always favored the neediest of peoples. When asked specifically about its possible negative role in the conflicts and sufferings of the previous millennium and its responsibility in present ones, he has emphatically denied it, once more against scientific fundamentalists.

Nevertheless, his take on religion as something irrational because not open to empirical verification is clearly reductionist. As pointed out by Kenneth Miller (2016), an evolutionary biologist and professor at Brown university, although an spiritual soul would not be part of the substance and matter of the brain - anymore than God is detectable by scientific means, it 
would give an account of all those processes and areas that Chomsky alludes to: the innate categorical imperative of conscience, whose authority is taken as personally absolute without any scientific proof but rather through intuitive knowledge; a conscience that judges our actions without any sensory stimuli; and the mystery of disinterested love, totally unexplained by the combination of biochemical elements or animal instinct, which always appreciates the intrinsic value of the individual person, including one's enemies. On the face of all this - and much more - phenomena like the lighting of the limbic system observed through magnetic resonance while experiencing love or some evolutionary psychological hypotheses about it do really come short off the mark. The latter, including concepts such as Reciprocal Altruism (Robert Trivers 1971), a mere adaptive biological solidarity geared toward survival and reproduction, which tend to be divulged as proven, are also sometimes the object of Chomsky's scorn, who labels them as "pop science". These phenomena may as well be related to the evolution of the subconscious instincts men also possess, like any other animal, but without being determined by them.

That disinterested love, which Chomsky really values as the most important thing in life as yet unexplained, ${ }^{5}$ may be a sign of the spiritual activity of an infused spiritual soul, intimately united to the body (cf. Escutia 2017). This soul would also give an account of some innate truths taken for granted -such as condemning the use of people as means to our ends because of their intrinsic dignity deriving from their rational and free nature.

Evolution can set the stage for what a spiritualized body can achieve. As Miller (2018) writes:

Our biological heritage is merely the beginning of what we can be, not the end of it. The understanding that we have our roots in the process of natural selection explains how our brains were shaped, but that does not undermine the independence of human nature or deny the reality of human knowledge and achievement. Evolution may explain the human need for art, music, religion, and even science, but it cannot explain those disciplines away. Each exists, in its

5 Check, for example, https://youtu.be/PRO-WE3GldQ 
highest form, as an expression of the best humanity can offer in making sense of this remarkable world. (p. 229-230)

In Christian theology, Miller (2016) also ventures to suggest that this soul would provide the basis for the immortality of the self, the freedom to make independent choices and the hope of our redemption. A mind based in matter, he states, is not a contradiction of any of these theological imperatives and, consequently, the advance of neuroscience could neither threaten nor disprove the existence of the soul.

\section{The emergence of spirit}

Let us now introduce a hypothesis about the infusion of the spiritual soul and its effects. We will follow C. S. Lewis'(2014b) approach in The Problem of Pain. This possible recreation is perfectly compatible with the sparse data brought about by scientific research so far. The point of departure is the reasonableness of God's existence, a conclusion reached philosophically and independently of any particular religion or divine revelation. Starting on in this way, one could conceive the following scenario derived by Lewis from the biblical revelation and abstracting away what lies behind the different images. He takes for granted an evolutionary process, somehow directed by God in the background.

For long centuries God perfected the animal form which was to become the vehicle of humanity and the image of Himself. He gave it (...) a brain sufficiently complex to execute all the material motions whereby rational thought is incarnated. The creature may have existed for ages in this state before it became man: it may even have been clever enough to make things which a modern archaeologist would accept as proof of its humanity. But it was only an animal because all its physical and psychical processes were directed to purely material and natural ends. Then, in the fullness of time, God caused to descend upon this organism, both on its psychology and physiology, a new kind of consciousness which could say 'I' and 'me', which could look upon itself as an object, which knew God, which could make judgements of truth, beauty, and goodness, and which was so far above time that it could perceive time flowing past. 
$[\ldots]$

Judged by his artefacts, or perhaps even by his language, this blessed creature was, no doubt, a savage. All that experience and practice can teach he had still to learn: if he chipped flints, he doubtless chipped them clumsily enough. He may have been utterly incapable of expressing in conceptual form his paradisal experience. (pp. 46-47)

As Lewis writes on, one cannot know how many of these creatures God made. Still, restricting ourselves to the emergence of language, which should be contemporary to the presence of a spiritual soul as it is one of the main features distinguishing humans from other animals, the original mutation responsible for its presence, according to Chomsky, would have occurred in some individual within a small group, who would transmit it to their progeny. As it would lead to more and better cooperation, those carrying the mutation would end up outsurviving the others.

This hypothesis is perfectly compatible with biblical data about the first humans communicating with one another, being self-conscious and admirers of their environment. In fact, Chomsky points out that language is the proof of an explicit self-consciousness because without it we can consciously manage neither our thoughts nor ideas. In this sense, language and self-consciousness might be contemporary and even have emerged at the same time. Humans' self-consciousness separates them radically from other animals and allows them to think universally, for example, about the concept of good in general, or the extinction of their race, to cast a retrospective look at the past or to think about leaving a better world to future generations.

Naturally, it is not being proposed that God's infusing the soul has caused the mutation and genetic-cognitive reorganization Chomsky talks about: in fact, this proposal would also appear to be compatible with a gradualist evolutionary hypothesis. ${ }^{6}$ Rather is it meant here that it may have been con-

6 Surprisingly, one must point out that, currently, the most famous evolutionary biologist, Richard Dawkins (2015, p. 382), a consummate gradualist himself, is ready to accept language, conceived as recursive syntax, as a possible saltationist exception (also see, for his own words on the matter: https://youtu.be/bow4nnh1Wv0: $\left.45^{\prime}-47^{\prime}\right)$. This is really surprising, as he had written (1995): "Without gradualness...we are back to a miracle", 
comitant with the rise of language as well as with the first representational and artistic manifestations of archeological finds. These coincide in time with our east-African ancestors' departure from Africa. Neither do we think Chomsky would back up such a proposal: it just is compatible with his hypothesis.

\section{The spirit's fall}

However, let us take a step further, which would lead us to correct Chomsky in his trust in human nature as that of Rousseau's "noble savage". There is no doubt of the superior insight, understanding and intelligence of our great linguist because not only can he see evil in the world but is also committed to an altruistic and public denunciation of it. Nevertheless, when it comes to human nature, it seems it is only the environment that corrupts people, as if they were naturally completely good. It is enough to see what happens in children's playgrounds to realize that this is not so. That is why, again with the elegant language of Lewis, we continue with the story to hypothesize what might have happened after the start of language.

We do not know how many of these creatures God made, nor how long they continued in the Paradisal state. But sooner or later they fell. Someone or something whispered that they could become as gods - that they could cease directing their lives to their Creator and taking all their delights as uncovenanted mercies, as "accidents" (in the logical sense) which arose in the course of a life directed not to those delights but to the adoration of God. [...] They desired to be on their own, [...], to "call their souls their own". But that means to live a lie, for our souls are not, in fact, our own. [...]. We have no idea in what particular act, or series of acts, the self-contradictory, impossible wish found expression. For all I can see, it might have concerned the literal eating of a fruit, but the question is of no consequence. This act of self will on the part of the creature, which constitutes an utter falseness to its true creaturely position, is the only sin that can be conceived as the Fall [...] something which a being free from the temptations of fallen man could conceivably have committed.

because, following Darwin (1859), that would be evidence of special creation as "nature takes no sudden leaps” ('Natura non facit saltum', 194)). 
[...] The mere existence of a self includes from the first, the danger of self-idolatry. [...] I must make an act of self-surrender, however small or however easy, in living to God rather than to myself. This is, if you like, the 'weak spot' in the very nature of creation, the risk which God apparently thinks worth taking. But the sin was very heinous, because the self which Paradisal man had to surrender contained no natural recalcitrancy to being surrendered. His data, so to speak, were a psychophysical organism wholly subject to the will and a will wholly disposed, though not compelled, to turn to God. The self-surrender which he practiced before the Fall meant no struggle but only the delicious overcoming of an infinitesimal self-adherence which delighted to be overcome - of which we see a dim analogy in the rapturous mutual self-surrender of lovers even now. He had, therefore, no temptation (in our sense) to choose the self, no passion or inclination obstinately inclining that way - nothing but the bare fact that the self was himself.

Up to that moment the human spirit had been in full control of the human organism. It doubtless expected that it would retain this control when it had ceased to obey God. But its authority over the organism was a delegated authority which it lost when it ceased to be God's delegate. [...] He began to rule the organism in a more external way, not by the laws of spirit, but by those of nature. Thus, the organs, no longer governed by man's will, fell under the control of ordinary biochemical laws and suffered whatever the inter-workings of those laws might bring about in the way of pain, senility and death. And desires began to come up into the mind of man, not as his reason chose, but just as the biochemical and environmental facts happened to cause them. And the mind itself fell under the psychological laws of association and the like which God had made to rule the psychology of the higher anthropoids. And the will, caught in the tidal wave of mere nature, had no resource but to force back some of the new thoughts and desires by main strength, and these uneasy rebels became the subconscious as we now know it.

'Dust thou art, and unto dust shalt thou return.' The total organism which had been taken up into his spiritual life was allowed to fall back into the merely natural condition from which, at his making, it had been raised [...]. Thus, human spirit from being the master of human nature became a mere lodger in its own house, or even a prisoner; rational consciousness became what it now is - a fitful spot-light resting on a small part of the cerebral motions. But this limitation of the spirit's powers was a lesser evil than the corruption of the 
spirit itself. It had turned from God and become its own idol, so that though it could still turn back to God, it could do so only by painful effort, and its inclination was selfward. Hence pride and ambition, the desire to be lovely in its own eyes and to oppress and humiliate all rivals, envy, and restless search for more, and still more, security, were now the attitudes that came easiest to it. It was not only a weak king over its own nature, but a bad one: it sent down into the psycho-physical organism desires far worse than the organism sent up in to it.

This condition was transmitted by heredity to all later generations, for it was not simply what biologists call an acquired variation; it was the emergence of a new kind of man - a new species, never made by God, had sinned itself into existence. The change which man had undergone was not parallel to the development of a new organ or a new habit; it was a radical alteration of his constitution, a disturbance of the relation between his component parts, and an internal perversion of one of them (pp. 48-50).

Sixty years after Lewis wrote those words, and more in tune with contemporary evolutionary science, philosopher and theologian Keith Ward (2008) writes the following about that same reality of the fall:

What some Christians call "original sin" can be seen, from an evolutionary perspective, as the decision by groups of early humans or even prehominids to realize their genetically inherent tendencies toward lust and aggression, at the expense of similarly inherent tendencies toward kinship bonding and altruism. Over generations, those destructive tendencies have "switched on" the relevant genetic mechanisms, until it has now become "human nature" to be selfish and aggressive.

Original sin, from an evolutionary point of view, consists in a natural inclination toward self-centered and destructive behavior, rooted in the genetic code of humans, switched on by repeated inculturation. Humans are essentially related to one another as parts of social communities and given responsible moral freedom. But the repeatedly reinforced behavior of past generations has repressed our altruistic genes, alienated us from a sense of the presence of God, and vastly increased the amount of human and animal suffering (p. 81).

This description of our nature seems closer to reality than that of the noble savage because it gives a better account of the misery all humans 
daily sow, cause, reap and carry around. In this way, in both the origin of language development as well as in the current moral condition of humans there might have been, respectively, a double mutation causing disorder in the state of things. The first one, genetic, proposed by Chomsky, would reorganize the brain and allow it to connect its conceptual structure with some receptive and expressive instruments. The second one, the fruit of a badly used freedom, would disorganize our self-control capacity, placing the self-conscious self before and above everything.

\section{Conclusion}

Chomsky has taught us something as intuitively evident as that there is no need to examine many natural languages in depth in order to study humans' innate capacity for language. One is enough, as all of them are a manifestation of one and the same faculty (excluding all those aspects of their use related to knowledge about the world, culture and society, which may be many and very interesting to research). In the same way, there is no need to examine eyes from different races of humans to study eyesight. Neither is it necessary from a Chomskyan perspective to examine multitudes of cultures to learn that there is a natural, human basis to the moral law sustaining all ethical codes even though their external manifestations may be different. This is acutely illustrated again by Lewis (2014b), in his statement that no civilization praises selfishness or admires treason, or capriciously grasping at any female (even those societies accepting polygamy), not to mention other more self-evident examples.

It is reasonable to think that Chomsky might agree with the fact that, just as there exist restrictions to the form a human language may take, which have nothing to do with those imposed by prescriptive grammar, ${ }^{7}$ so there also are limits with respect to the possible forms a particular moral

7 The difference between the errors in, say, cat the dog bit the and you and me should get together, where the former is structurally impossible and the latter goes against an etiquette norm which would push for the subject "having to be" you and I (instead of me) even though most people do not talk like that. 
code may adopt and both crucially depend on the existence of the human nature he so adamantly defends.

Nothing new under the sun here, just another qualified viewpoint. At heart it is a reflection on what has helped so many generations to seek meaning and feel somehow special on realizing their divine creatureliness. This search employs that self-consciousness, so often linguistic in nature, as Chomsky points out, which, on the other hand, is such an unexpected reality in evolutionary terms since its computations require so much of our energy. And as the honest and agnostic Chomsky states, the point is that in science there is still much to be discovered and a lot of humility is needed in the face of mystery because science alone cannot explain the questions that matter most to us. Just recently, when asked by a youth in a university auditorium about the relationship between science and happiness, he answered that science can only deal with simple things and will never be able to answer the great questions in life, whose answers he encouraged him to seek somewhere else. ${ }^{8}$ That was a question stemming from the person's innate desire of the absolute, which, as also Lewis (2014b) explains with respect to other innate desires, must be satisfied in some existing reality, though at times one may not seem to find it easily. Chomsky's answer to that student is both a great consolation and a piece of advice for those of us who will never get to be enlightened enough, especially coming from someone who really is.

\section{References}

Berwick, Robert C. \& Chomsky Noam. 2016. Why Only Us: Language and Evolution. The MIT Press Cambridge, Massachusetts.

Bolhuis Johan, Tattersall Ian, Chomsky Noam, Berwick Robert C. 2014: "How Could Language Have Evolved?” PLoS Biol 12(8): e1001934. https://doi.org/10.1371/ journal.pbio.1001934

Chomsky, Noam. 1975. Reflections on language. New York: Pantheon.

8 Check https://youtu.be/iFB5oO9lEwQ 71' 
Chomsky, Noam. 1992. Chronicles of Dissent. Interviews with David Barsamian. Monroe: Common Courage Press.

Chomsky, Noam. 2005. “Three factors in language design.” Linguistic Inquiry, Volume 36, Number 1, Winter 2005: 1-22.

Chomsky, Noam. 2010. The Chomsky Sessions. Interview with Michael Albert. Science, Religion and Human Nature. Accessed April 2019 at https://archive.org/details/ ChomskyZMagazine

Chomsky, Noam. 2011a. "Language and Other Cognitive Systems: What is Special about Language?” University of Cologne lecture. Accessed April 2019 at https:// youtu.be/6i_W6Afed2k

Chomsky, Noam. 2011b. "The machine, the ghost, and the limits of understanding: Newton's contributions to the study of mind.” University of Oslo lecture. Accessed April 2019 at https://youtu.be/D5in5EdjhD0

Chomsky, Noam. 2012a. The Science of Language: Interviews with James McGilvray. Cambridge. CUP.

Chomsky, Noam. 2012b. “Grammar, mind and body: a personal view.” Lecture at the University of Maryland, College of Arts and Humanities. Accessed April 2019 at https://youtu.be/wMQS3klG3N0

Chomsky, Noam. 2016a. “On the evolution of language: a biolinguistics perspective.” Interview accessed April, 2019 at: http://www.truth-out.org/opinion/item/37725noam-chomsky-on-the-evolution-of-language-a-biolinguistic-perspective Chomsky, Noam. 2016b. “Language, Creativity, and the Limits of Understanding.” Lecture at UR Humanities Project. Accessed April, 2019 at https://youtu.be/ XNSxj0TVeJs

Ding Nai, Melloni Lucia, Zhang Hang, Tian Xing, Poeppel David. 2016. “Cortical tracking of Hierarchical linguistic structures in connected speech.” Nature Neuroscience 19: 158-164.

Darwin, Charles. 1859. On the Origen of Species. London: John Murray.

Dawkins, Richard. 1995. River out of Eden. New York: Basic.

Dawkins, Richard. 2015. Brief Candle in the Dark: My Life in Science. New York: Ecco-Harper and Collins publishers.

Escutia, Marciano. 2017. "The will to love that makes a difference." Sciencia et Fides 5, 2: 1-14.

Fitch, William T., Hauser, Marc and Chomsky, Noam. 2005. "The evolution of the language faculty: clarifications and implications.” Cognition 97(2): 179-210.

Hauser, Marc H., Chomsky Noam, Fitch, William T. 2002. “The Faculty of Language: What Is It, Who Has It, and How Did It Evolve?” Science 298, 1569. 
Lewis, Clive S. 2014a (eBook version: originally published in 1943). The Abolition of Man. Samizdat University Press. Québec. Accessed April 2019 at http://www. samizdat.qc.ca/cosmos/philo/AbolitionofMan.pdf

Lewis, Clive S. 2014b (eBook version: first published in 1952). Mere Christianity. Samizdat University Press. Québec. Accessed April 2019 at http://www.samizdat. qc.ca/vc/pdfs/MereChristianity_CSL.pdf

Lewis, Clive S. 2016 (eBook version: originally published in 1940). The Problem of Pain. Samizdat University Press. Québec. Accessed April 2019 at http://www. samizdat.qc.ca/cosmos/philo/PDFs/ProblemofPain_CSL.pdf

Miller, Kenneth 2016. What makes us humans: a biologist and a philosopher discuss at MIT. Accessed on April 1 ${ }^{\text {st }}, 2019$ at https://youtu.be/jYibo0cPs7A

Miller, Kenneth 2018. The Human Instinct: How We Evolved to Have Reason, Consciousness and Free Will. New York: Simon \& Schuster. Kindle edition.

Miyagawa, Shigeru, Lesure, Cora \& Nóbrega, Victor. 2018. “Cross-Modality Information Transfer: A Hypothesis about the Relationship among Prehistoric Cave Paintings, Symbolic Thinking, and the Emergence of Language.” Frontiers in Psychology 9.

Smith, Neil. 1999, 2004. Chomsky’s ideas and Ideals. Cambridge: Cambridge University Press.

Ward, Keith. 2008. The Big Questions in Science and Religion. Templeton Press. Kindle edition. 